\title{
Experimental Study of CMS Conductor Stability
}

\author{
P.Fabbricatore (1), S.Farinon (1), F.P.Juster (2) R.Musenich (1) and C.Priano (1) \\ (1) INFN, via Dodecaneso 33, I-16146 Genova, Italy, (2) CEA Saclay, Dapnia, Gif/Yvette, France
}

\begin{abstract}
Several computations have been carried out in last years to evaluate stability against disturlbances of the CMS coil. The results coming from finite element analysis have shown that the Minimum Quench Energy is between 0.43 and $0.85 J$ depending on the model describing the transition from superconducting to nomal state. The corresponding Mimimum Propagating Zone is quite short, ranging between 10 and $20 \mathrm{~cm}$. This very sloort MPZ allows to perform experimental measurements on short samples. This has been done using circular samples ( $400 \mathrm{~mm}$ in diameter) energized to $20 \mathrm{kA}$ by the transformer method. The applied field ranging between 3.5 and $6 \mathrm{~T}$, is provided by the Ma.Ri.S.A. focility at INFN Genova. A comparison between computations and experimental results is presented.
\end{abstract}

\section{INTRODUCTION}

For stability we mean the ability of a superconducting coil or conductor to absorb a disturbanec (local or distributed) without quenching. The transient analysis is needed to analyze the dynamic thermal and electrical processes occutring inside the winding after a heat release causes a local normal zone. In this case a small area of the winding becomes normal and the current starts to flow in the matrix causing ohmic dissipation. If the conductor is able to recover the superconducting state the coil is stable, otherwise the tratnsited length starts to grow and the coil quenches. Following Wilson [1] we can introduce two important parameters: the Minimum Propagation Zone (MPZ) and the Minimum Quench Energy (MQE).

The MPZ is defined as a normal tesistive zone in metastable thermal equilibrium with the superconducting zone around it. If a normal zone is bigger than the MPZ, the magnet will quench, if it is smaller it will recover to the superconducting state. The MQE is the minimum energy required to generate a MPZ. When performing transient analysis, we have to consider that the problem is three-dimensional, the medium is highly non-homogeneous and, at low temperatures, the thermal propecties of the materials strongly depend on temperature. These conditions lead to solve the heat transient diffusion equations by using a finite element code. Our method consists in imposing a given disturbance of given energy and length and solving the equation describing how the normal zone (if any normal zone is created) increases causing a quench, or reduces restoring a full superconducting state. The codes involved are HEATING 7.3 and CASTEM. This approach was tested comparing calculated and experimental MQE for a coil model of DELPHI magnet [2]. In this paper we will discuss a new comparative study between experimental results and

Manuscript received steptentser 27, 1999

P.Fabbricatore, Phone 39-0103536340, Fax 39-010-313358, e-mail Fabbticatore@ge.infi.it prediction of finite eloment codes. In this case the systen under analysis is not as complex as a coil. We will show that, the relative simplicity of the system allows both a better understanding of experimental results and a reliable application of FEA.

\section{TRANSIENT ANALYSIS STUDJES ON CMS COIL}

In this section we will briefly summarize the most updated FEA results of the transient response to localized disturbances in CMS coil. Let's recall some basic parameters. The current sharing temperature $T_{\mathrm{g}}$ is defined as:

$$
\mathrm{T}_{\mathrm{g}}=\mathrm{T}_{\mathrm{c}}(\mathrm{B})-\left[\mathrm{T}_{\mathrm{c}}(\mathrm{B})-\mathrm{T}_{0}\right] \frac{\mathrm{I}_{\mathrm{n}}}{\mathrm{I}_{\mathrm{c}}(\mathrm{B})}
$$

where $T_{0}$ and $I_{\varepsilon}$ are the critical temperature and the critical current at the operating magnetic field $B$ [3]:

$$
\left\{\begin{array}{l}
T_{c}(B)=T_{c 0}\left(1-\frac{B}{B_{c 20}}\right) \\
I_{c}(B)=I_{c}(1-0.096 \mathrm{~B})
\end{array}\right.
$$

For a NbTi conductor the critical temperature at zero applied field is $\mathrm{T}_{\mathrm{c} 0}=9.25 \mathrm{~K}$ and the second critical field is $\mathbf{B}_{c 20}=13.9 \Gamma$. The CMS operating current and temperature are: $\mathrm{I}_{\mathrm{m}}=19.5 \mathrm{kA}$ and $\mathrm{T}_{\mathrm{d}}=4.5 \mathrm{~K}$. From magnetic computation the conductor peak field (self field plus applied field) is $\mathrm{B}=4.6 \mathrm{~T}$. The critical current at peak field and operating temperature is Ic $=56 \mathrm{kA}$. By using those numbers we found:

$$
\left\{\begin{array}{l}
\mathrm{T}_{\mathrm{c}}(\mathrm{B})=7.35 \mathrm{~K} \\
\mathrm{~T}_{\mathrm{g}}(\mathrm{B})=6.35 \mathrm{~K}
\end{array}\right.
$$

Basic assumptions of the codes are:

- the material thermal properties are described as function of temperature and magnetic field: thermal conductivity $K=K(T, B)$, electrical resistivity $\rho=\rho(B, T)$ and specific heat $\mathrm{C}_{\mathrm{p}}=\mathrm{C}_{\mathrm{p}}(\mathrm{T})$;

- the system is adiabatic and the initial temperature is fixed and uniform;

- the thermal disturbance is modeled as a constant power dissipated for a given time in a given region.

- the heat generation is temperature dependent. For T<Tc we have no dissipation, as $\mathrm{T}>\mathrm{T}_{\mathrm{g}}$ the current starts flowing into the $\mathrm{Al}$ matrix causing a Joule dissipation per unit volume.

The last assumption is correct if we assume that the exceeding current can be shared instantaneously by the whole Al-matrix, but because of the eddy curtents this is not true. The appropriate way to describe the heat generation is in term. of diffusion of the electrical field according to the equation:

$$
\Delta \overrightarrow{\mathrm{E}}=\frac{\mu_{0}}{\rho_{\mathrm{e} f \mathrm{f}}} \frac{\partial \overrightarrow{\mathrm{E}}}{\partial \mathrm{t}}
$$


In HFATING we assume that the heat generation starts when $T \geq \frac{T_{g}+T_{c}}{2}$ imposing the dissipation calculated by solving. (4) with the linite element code ANSYS. The time dependent dissipation is shown in Fig. 1 . In CASTEM, both effects, current sharing and diffusion are taken into account. The model for the numerical computation schematised the winding as a parallelepiped where the plane $X-Y$ represents a smail portion of the Z-R section of the coil, and the longitudinal direction $Z$ represents the coil azimuthal direction. Fig. 2 shows the used model.

Three different cases, with different locations of the distutbance, are studied:

- inside a single conductor ,

- near the Al-6061 reinforcement of the CMS conductor (simulating a crack in the resin at the jnterface with the Al-6061 reinforcement),

- between two cables with some epoxy resins in-between (simulating a crack of the inter layer insulation).

In Fig. 3 a typical time evolution of the normal zone calculated by using HEATING (for case 1 ) is shown. The squares show a transited zone, generated by a disturbance of $0.621 \mathrm{~J}$, which recovers to the superconducting state, while the circles show that for a bigger energy the transited length grows causing the quench. From those calculations we can also estimate the MPZ length, $12 \mathrm{~cm}$, which devetops in only $5 \mathrm{~ms}$. In Fig.4 the quench energy for different pulse duration is ploted. From these calculations we found a MQE of $0.62 \mathrm{~J}$ by using HEA'IING and $0.75 \mathrm{~J}$ by using CASTEM.

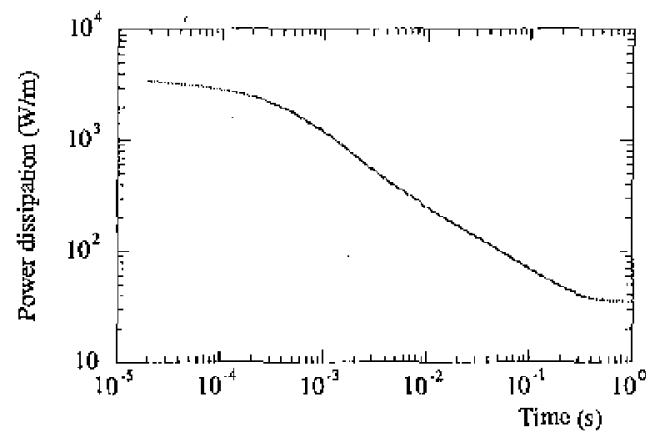

Jig. ]. Time dependent hent dissipation cue to the cutrent diffusion.

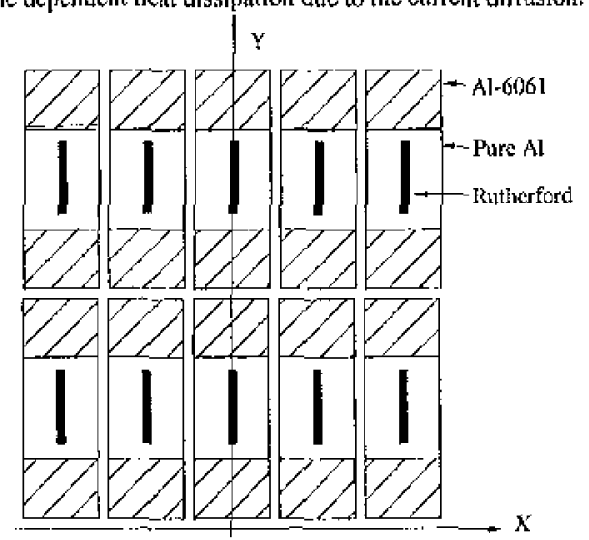

Fig. 2. $\mathrm{X}-\mathrm{Y}$ section of the CMS witdiltg model. The space between conductors is filled with fiber glass eproxy.
Same calculations have been carried ont for case 2 . We found a MQE of $3.51 \mathrm{~J}$ (see results in Fig.5). For case 3 we found a MQE of 8.34J (Fig.6). In Table I, these results are summarised.

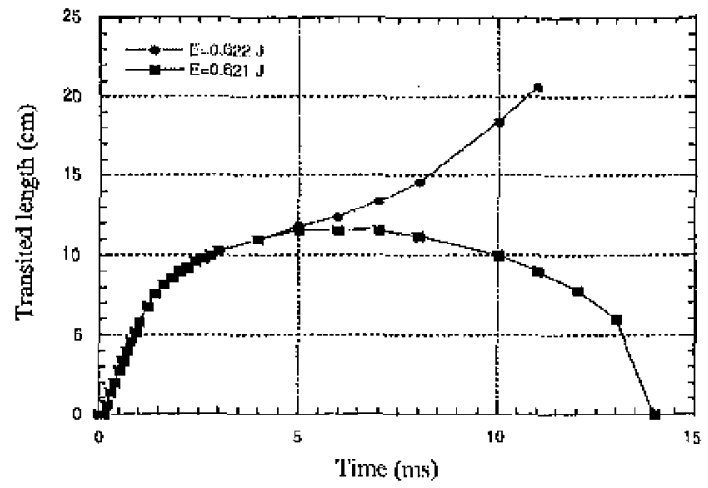

Fig. 3. Time evolution of the nonmal zone calculnted for a disturbance of lns duration and lom lengh.

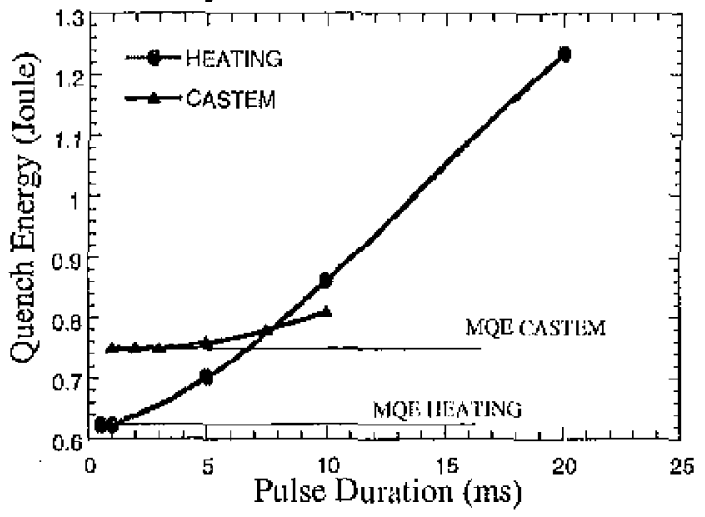

Fig. 4. Comparison of ule quanch energy vs. pulse duration calculated by using the two codes.

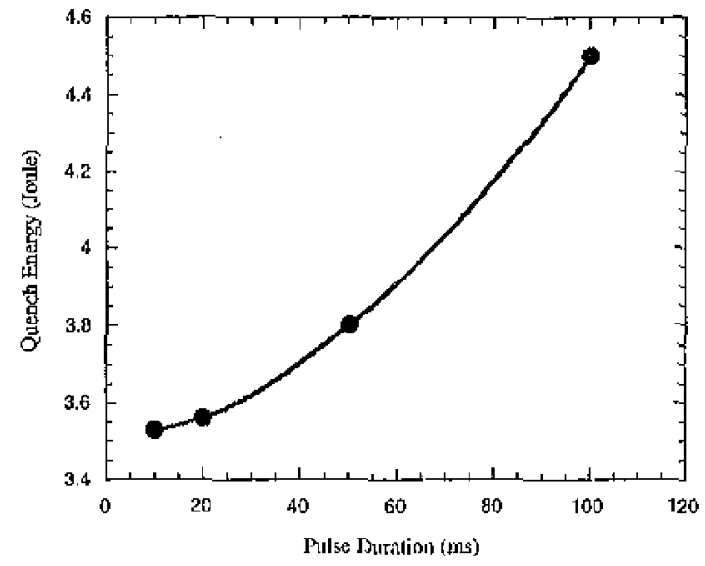

Fig. ร. CMS quench anergy in case of tesilu crack at Al-alloy interface.

TABLE I

SUMMAKY OF FEA RESULTS FOR CMS COLL STABIETTY

\begin{tabular}{ll} 
CASE & MQE \\
\hline Disturb inside conductor & $0.62 \mathrm{~J}$ \\
Crack in the resin at Al-alloy inter face & $3.51 \mathrm{~J}$ \\
Inter-layer resin crack & $8.34 \mathrm{~J}$ \\
\hline
\end{tabular}




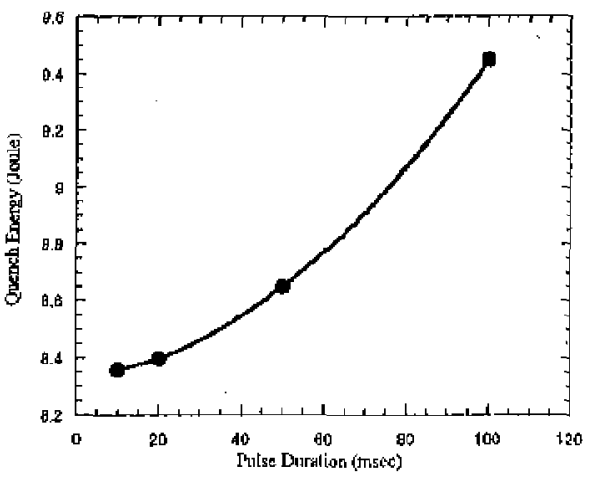

Fig. 6. CMS quench energy for an interlayer resin erack.

These calculations are very important for the coil design becalse we have found that we can have higher level of disturbance in insulation with respect to disturbance inside conductor (a factor 13 in MQE).

It is interesting to perform a check of the ability of the IIEATING code in predicting quench energy of known systems. Some time ago we performed this kind of test, by evaluating the MQE of a mock-up coil of DELPHI magnet [2]. Presently we want to make a more relevant test on a system including a CMS type conductor.

\section{TEST SAMPLE AND EXPERIMENTAL SET-UP}

A special sample has been developed (at CEA and INFN) for test in the Ma.Ri.S.A. facility at INFN-Genova [4]. The sample, schematically shown in Fig. 7, is made of an external Al-Alloy ring (Height $=70 \mathrm{~mm}, 0 . \mathrm{D} .=438 \mathrm{~mm}$, I.D. $=428 \mathrm{~mm}$ ) containing an $\Lambda l$ stabilized conductor $(70 \times 35 \mathrm{~mm})$, mechanically coupled through a soft-soldering process. The superconducting part is a Rutherford cable composed of 32 strands with Copper/SC ratio $1.25 / 1$. The sample has been designed in order to have a maximum deformation of $1.5 \%$ when charged at 50kA in a $4.0 \mathrm{~T}$ magnetic field. This was done in order to perform critical current measurement in mechanical conditions similar to CMS coil. For its mechanical properties, and electrical configuration, this sample can be considered as a good example of CMS-type reinforced conductor (though the lay.-out is considerably different from actual CMS conductor). The sample was connected to the sample holder taking care to minimize the mechanical interaction between them (Fig. 8). The current is induced in the sample using the direct transformer method [5]: the magnet is the primaty winding of the transtormer and the sample the secondary one. The sample is indirectly cooled by He vapors at $4.2 \mathrm{~K}$.

The current flowing in the sample is determined by selffield measurements using a Hall probe placed just over the conductor in order to minimize the signal due to the external field, and maximize the self-field signal. Two voltage taps are soldered at the sample. As shown in Fig.9 the signal passes through a low noise amplifier and is then measured by a National Instruments DAQ board. An electrically isolated heater is glued to the internal part of the conductor.

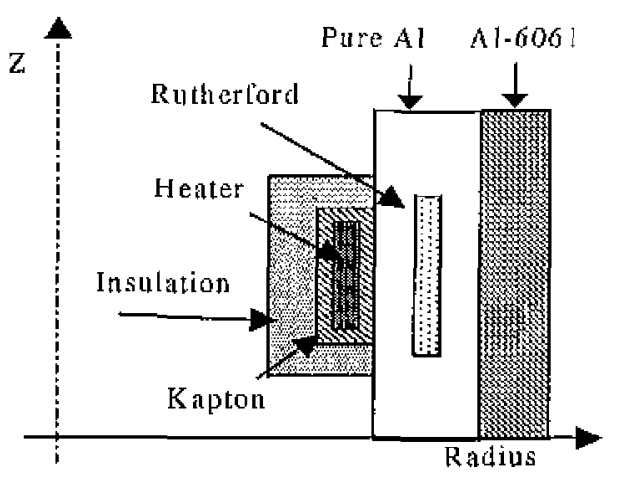

Fig. 7. Z-R section of the simple holder.

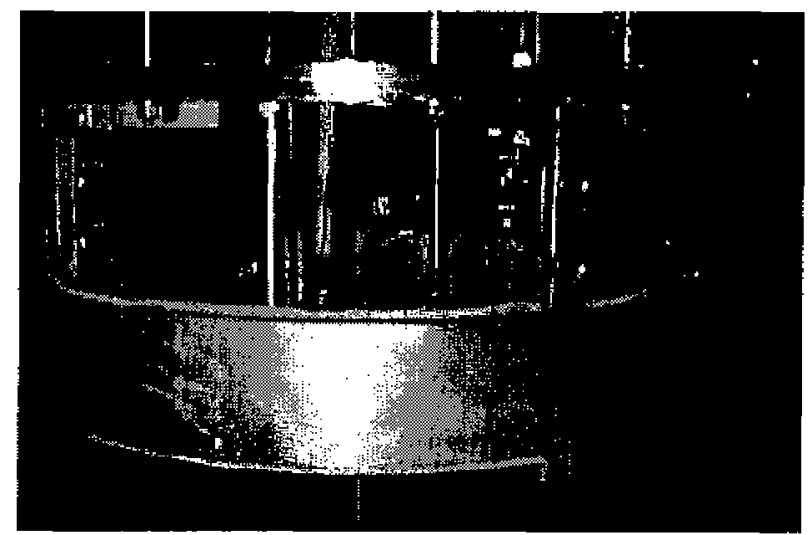

Fig. 8. Sample-lodeler.

The heater is used to give bent pulse to the conductor. $\mathrm{At}$ a fixed value of external field, sample current and temperature, a single square signal is sent to a power amplifier, which supplies current to the heater. The disturbance energy is determined by the pulse time (otder of some ms) at fixed power (up to $750 \mathrm{~W}$ ). During and after each distubance the voltage signal (see Fig.10) is monitored to verify if a quench occurs. When the signal is sent to the heater, a trigger signal is sent to the DAQ board. It starts to measure the voltage signal at a scan rate of $1000 \mathrm{~Hz}$. The measurements are then stored in a PC.

\section{LXPERIMENTAL RESULTS AND SMULLATIONS}

As first step, the critical current of the sample was measured, in order to be sure to perform the stability experiment at a current level $35 \%$ of critical current (as in CMS coil). We measured a critical current of $60 \mathrm{kA}$ at $\mathrm{B}=4.5 \mathrm{~T}$ and $T=4.22 \mathrm{~K}$. As a consequence measurements performed around $21 \mathrm{kA}$ and $4.5 \mathrm{~T}$ are those ones closer to the actual CMS coil condition. Measutements include different sample currents and external fields. Results are shown in Table II. In this kind of experiment it is important to know how the disturbance is seen by the conductor. Sume information comes from the analysis of the signal at voltage taps. Fig.10 shows a typical signal for a disturbance inducing a quench. 'l'he time delay from $t=0$ (pulse statts at generator) at the quench time is an important parameter. 


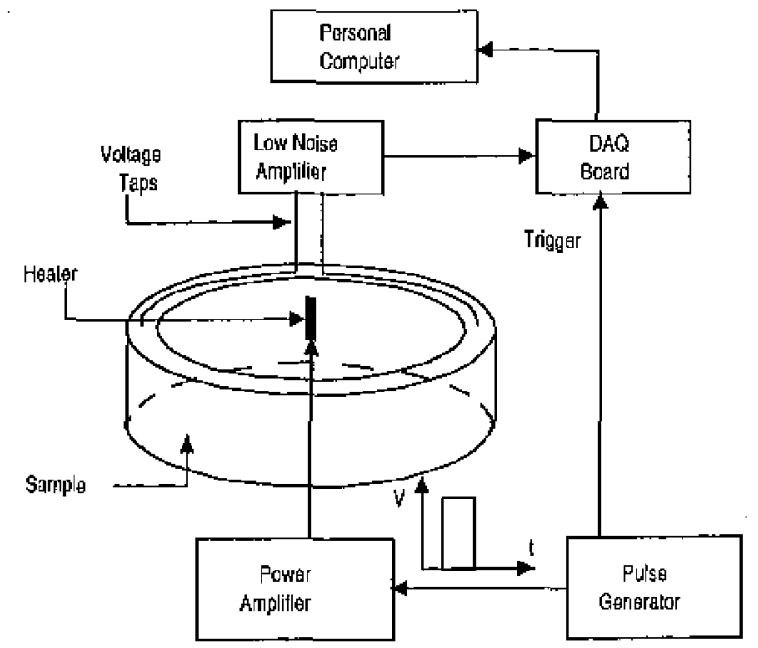

Fig. 9. Block diagran of the measurements system.

The defay ( $50 \mathrm{~ms}$ in our case) is related to the time needed by heat to diffuse through the insulation surrounding the heater. When performing simulations we sized the insulation between heater and sample just to fit the measured time delay. In this frame it can be interesting to look at the broadening of the disturbance. Fig. 10 shows the result of a computation of heat diffusion through the heater, the pure aluminium and the Rutherford: in particular one can see how a disturbance, given in $5 \mathrm{~ms}$ at the heater, is seen by the SC cable in adjabatic conditions. The energy release occurs in a time of about $1 \mathrm{~s}$; $22 \%$ of energy in the first $50 \mathrm{~ms}$ and $33 \%$ in the first $100 \mathrm{~ms}$; i.e. we have to wait some time before a significant energy is transferred to the SC cable. Another aspect of measurement is related to the sample cooling. Since the sample is not in vacuum, but is directly cooled by helium vapor, we had to include the heat transfer to Ie gas. FEA results and comparisons with the experimental ones are shown in Table II.

In order to demonstrate that the measured quench energy is the MQE, we had to give both shorter disturbances at the same measured quench energy and higher disturbances in longer time.

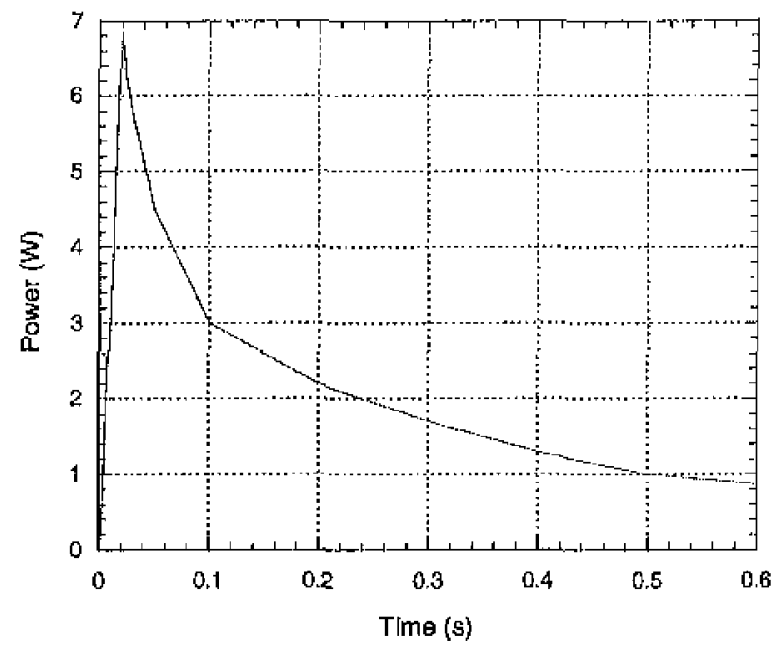

Fig. 10. Calculated power in the Rutherford cable for a disturbance given at the heater in $5 \mathrm{mts}$
TABLE II

RESULTS FROM LXPERIMENT WITH SAMPLE COOLED HY GAS

\begin{tabular}{|c|c|c|c|c|c|c|}
\hline Meas. & $\begin{array}{c}\text { Curr. } \\
\text { (A) }\end{array}$ & $\mathrm{B}$ (T) & $\Delta t$ (ms) & $\begin{array}{l}\text { Energy } \\
(\mathrm{J})\end{array}$ & Quench & $\begin{array}{l}\text { Calc. } \\
\text { values }\end{array}$ \\
\hline A & 30000 & 4.62 & $\begin{array}{l}5 \\
8\end{array}$ & $\begin{array}{l}3.8 \mathrm{~J} \\
6.0 \mathrm{~J}\end{array}$ & $\begin{array}{l}\text { NO } \\
\text { YES }\end{array}$ & $4.8 \mathrm{~J}$ \\
\hline B & 28600 & 4.42 & $\begin{array}{l}8 \\
9\end{array}$ & $\begin{array}{l}6.0 \mathrm{~J} \\
6.8 \mathrm{~J}\end{array}$ & $\begin{array}{l}\text { NO } \\
\text { YES }\end{array}$ & $5.5 \mathrm{~J}$ \\
\hline C & 25000 & 4.80 & $\begin{array}{c}9 \\
10 \\
\end{array}$ & $\begin{array}{l}6.8 \mathrm{~J} \\
7.5 \mathrm{~J} \\
\end{array}$ & $\begin{array}{l}\text { NO } \\
\text { YES }\end{array}$ & $5.0 \mathrm{~J}$ \\
\hline D & 23200 & 4.12 & $\begin{array}{c}5 \\
10 \\
\end{array}$ & $\begin{array}{l}3.8 \mathbf{J} \\
7.5 \mathrm{~J}\end{array}$ & $\begin{array}{l}\text { NO } \\
\text { YES }\end{array}$ & $6.8 \mathrm{~J}$ \\
\hline $\mathrm{E}$ & 21500 & 4.88 & $\begin{array}{c}9 \\
10 \\
\end{array}$ & $\begin{array}{l}6.8 \mathrm{~J} \\
7.5 \mathrm{~J} \\
\end{array}$ & $\begin{array}{l}\text { NO } \\
\text { YES }\end{array}$ & $5.4 \mathrm{~J}$ \\
\hline F & 21200 & 4.31 & $\begin{array}{l}7.5 \\
10 \\
\end{array}$ & $\begin{array}{l}5.6 \mathrm{~J} \\
7.5 \mathrm{~J} \\
\end{array}$ & $\begin{array}{l}\text { NO } \\
\text { YES }\end{array}$ & $6.5 \mathrm{~J}$ \\
\hline & 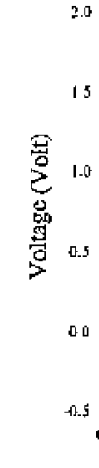 & & Tim & 600 & רו- & wes \\
\hline
\end{tabular}

Fig, 11. Typical quench detection measure

Unfortunately we are limited by the amplifier power and by the fact that this kind of measurement is significant only if the Minimum Propagating Zone is localized. For disturbances longer than $10 \mathrm{~ms}$ at the heater, the MPZ is longer than our sample $(1.3 \mathrm{~m})$, and, consequently the measurement makes no more sense. However the experimental data are very close to simulations, so that we can state that the use of FD $\Lambda$ helps in giving a satisfactory representation of dynamic processes occurring during localized transition to normal state. On this base we can issume that the computed Minimum Quench Energies of CMS coil (as shown in Figs. 3 to 6 ) aro basically correct. In fact these values were taken into consideration when evaluating the possible disturbance spectrum in CMS coil [6].

\section{REFLRENCES}

[1] M. N. Wilson, Superronduning Magnet, Oxford: Oxford Intwersity Press, 1983

[2] F. Juster, J.C.Lotin, L.Boldi, R.]Te Lorcnzi, P.Fabricatore, R.Musenich, D.E.Baynham, P.L.Sampson, IEEE Trass, on Appl. Superronductivity, Vol.5, N. 2, P.337, 1905

[3] M.S. Lubel, ILLE Trans.Mag, Mag-19, No 3 p.754-757 (1983)

[4] P. Fabbricatore, R. Muscnich, C.Priane, E.Sirola MT15 Procecdings, Pant2, p. 1307

[5] P. Fabbreatore, R.Musenich Handhook of Applied Superconductivity B7.4 , p. 324, IOP Bristol 1998

[6] CMS Coil Collaberation, Proteding of The Magnet Project LDR, Folitor F. Kiteher CEASaclay CMS Doc. 1998-148 